\title{
Surveillance of childhood vaccine- preventable diseases at health facilities in Jeddah, Saudi Arabia
}

N.K.R. Ibrahim ${ }^{1,2}$ and H.M. Al Bar ${ }^{2}$

$$
\begin{aligned}
& \text { ترصُّد الأمر اض الممكن توقِّها باللقاح لدى الأطفال في المرافق الصحية في جدة، المملكة العربية السعودية } \\
& \text { نهلة خميس رجب إبراهيم، حسين محمد البار }
\end{aligned}
$$

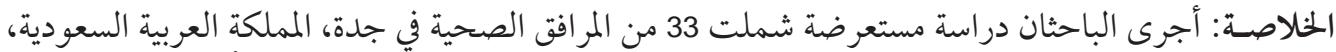

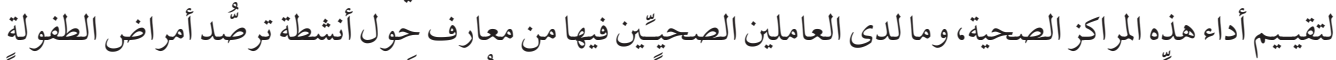

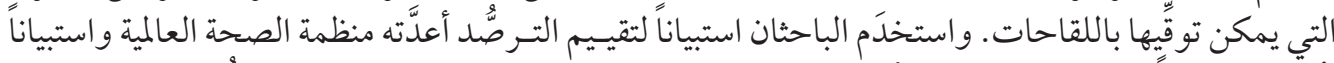

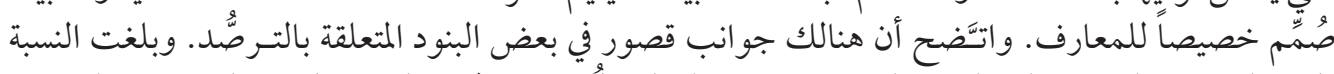

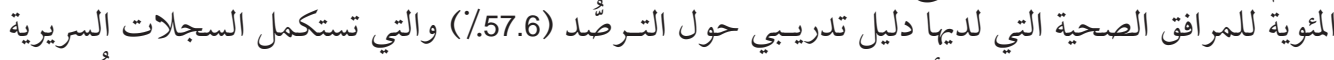

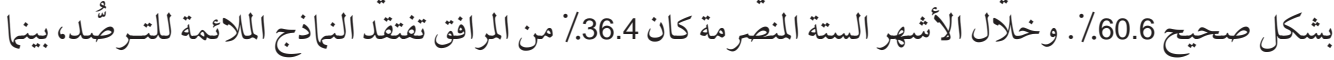

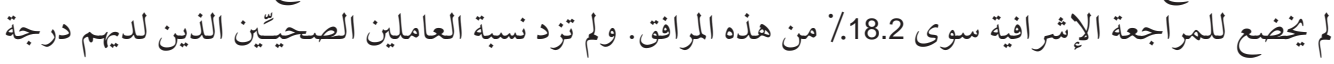

$$
\begin{aligned}
& \text { تبعث على الرضى من المعرفة عن الربع. }
\end{aligned}
$$

ABSTRACT A cross-sectional study was conducted at 33 randomly selected health facilities in Jeddah, Saudi Arabia, to assess health facilities' performance and health workers' knowledge of surveillance activities for childhood vaccine-preventable diseases. The WHO surveillance assessment questionnaire and a specially designed knowledge questionnaire were used. There were deficiencies in some surveillance items. The percentages of health facilities that had the surveillance manual and correctly filled clinical registers were $57.6 \%$ and $60.6 \%$ respectively. In the 6 months preceding the study, $36.4 \%$ of facilities lacked the appropriate surveillance forms while only $18.2 \%$ had received supervision reviews. Only one-quarter of health workers had a satisfactory knowledge score.

\begin{abstract}
Surveillance des maladies de l'enfant à prévention vaccinale dans des établissements de santé de Djeddah (Arabie saoudite)

RÉSUMÉ Une étude transversale a été menée dans 33 établissements de santé de Djeddah (Arabie saoudite) choisis au hasard, afin d'évaluer l'efficacité de ces établissements et les connaissances des professionnels de santé en matière d'activités de surveillance des maladies de l'enfant pouvant être évitées par la vaccination. On a utilisé le questionnaire d'évaluation de la surveillance mis au point par l'OMS et un questionnaire spécial sur les connaissances. Certains items ont révélé des points faibles. Les pourcentages d'établissements de santé qui disposaient du manuel relatif à la surveillance et qui remplissaient correctement les registres cliniques étaient respectivement de $57,6 \%$ et $60,6 \%$. Six mois avant l'étude, $36,4 \%$ des établissements ne possédaient pas les formulaires de surveillance adéquats et seuls $18,2 \%$ avaient reçu des rapports de supervision. Seuls un quart des professionnels de santé obtenaient un score de connaissances satisfaisant.
\end{abstract}

${ }^{1}$ Department of Epidemiology, High Institute of Public Health, University of Alexandria, Alexandria, Egypt (Correspondence to N.K.R. Ibrahim:nahlakhamis@yahoo.com).

${ }^{2}$ Department of Family and Community Medicine, Faculty of Medicine, King Abdelaziz University, Jeddah, Saudi Arabia. Received:06/06/06; accepted: 28/12/06 


\section{Introduction}

The threat of communicable diseases is reemerging in developed countries [1], while in the Eastern Mediterranean Region these diseases are still the most common causes of death, disability and illness [2]. Developing effective and efficient national surveillance and response/control systems is important for national, regional and global health security $[2,3]$.

Public health surveillance is "the ongoing systematic collection, analysis, interpretation and dissemination of data regarding a health-related event" [4]. Data dissemination by public health surveillance systems can be used for immediate public health action, programme planning and evaluation, and formulating research hypotheses $[4,5]$. Successful communicable disease surveillance depends on effective bidirectional flow of information between the local level of health care and communicable disease control units at regional, national and global levels [6].

Childhood immunization programmes are incomplete without proper surveillance of vaccine-preventable diseases (VPD) [7]. Such surveillance makes it possible to estimate the burden of diseases, decide about the appropriate policies to reduce these diseases, identify pockets of susceptibility and control potential outbreaks [8]. In Saudi Arabia, the Expanded Programme on Immunization (EPI) provides vaccination against the major childhood diseases [9]. However, evaluations of the surveillance system at the health facility level have been limited in scope and content. The aim of this study, therefore, was to assess the surveillance system for childhood VPD at the health facility level in Jeddah governorate, and to determine the knowledge of health care workers about VPD surveillance.

\section{Methods}

\section{Study design}

A cross-sectional study was conducted at 33 randomly selected health facilities in Jeddah governorate during the period December 2005 to February 2006. The focus of this assessment was on childhood VPD, namely tuberculosis, hepatitis B, poliomyelitis, diphtheria, pertussis, tetanus, measles, mumps, rubella and meningitis (as Haemophilus influenza type $\mathrm{b}$ is the commonest cause of bacterial meningitis in children aged 2 months to 5 years in this area).

\section{Sample}

The sample included 27 primary health care (PHC) units, randomly selected from a total of 38 PHC facilities from all 6 Ministry of Health supervision districts by the proportional allocation technique. Also, 3 private and 3 government hospitals were randomly selected from a list of all hospitals in Jeddah.

\section{Data collection}

The data were collected using 2 questionnaires.

\section{Assessment of national communicable} disease surveillance and response system The WHO generic questionnaire for assessment of national communicable disease surveillance and response systems at health facility level was used [10], with some modifications to be specific for assessment of childhood VPD. It was completed by the person in charge of surveillance at each health facility, usually a health inspector but sometimes a nurse or doctor. The questionnaire included both interview and observation items. Questions were asked about the efficacy and quality of the surveillance system in addition to observing and checking the presence of important materials needed for the surveillance system. 
The following items were assessed:

- Information sources (presence of national surveillance manual; presence of standard case definitions for childhood VPD).

- Clinical registry (presence of clinical registers; whether registers filled correctly).

- Case detection (presence of materials for collecting, storing and transporting specimens for suspected cases of VPD).

- Case reporting (lack of appropriate surveillance forms in the preceding 6 months; whether last monthly report agrees with the clinical register for diseases targeted for eradication, diseases targeted for elimination, epidemic-prone diseases and any country-priority disease; presence in the preceding 3 months of 12 weekly reports and 3 monthly reports; whether weekly reports submitted on time).

- Data analysis (presence of data analysis of VPD cases by place, time and line graphs; presence of action threshold for 1 country-priority disease; presence of demographic data used as denominators).

- Epidemic preparedness (presence of a written case management protocol for 1 epidemic-prone disease).

- Epidemic response (whether prevention and control measures are implemented based on local data).

- Assessment of feedback (presence of at least 1 feedback bulletin or report on surveillance from a higher level in the preceding 1 year).

- Assessment of supervision (presence of at least 1 written supervision report from a higher level in the preceding 6 months).

- Training (whether respondent ever received training on surveillance).
- Adequacy of resources (presence of stationery, computers, statistical packages, e.g SPSS or Epi-Info, faxes and motor vehicles).

\section{Knowledge about surveillance for childhood VPDs}

The second questionnaire was a predesigned interview questionnaire for assessing the knowledge of health care workers about surveillance for childhood VPDs and related topics. All health care workers involved in preventive care who were available on the day of the study and agreed to participate were included in the study. The questionnaire consisted of 2 sections; the 1st section enquired about personal data: sex, educational level and job and whether any training on surveillance had been received. In the 2nd section, the knowledge of health workers about different items of surveillance was assessed. The knowledge items consisted of 26 open-ended questions about:

- Definition of surveillance.

- Definition of international notification weeks and the number.

- Diseases under EPI, their definitions, with examples (suspected and confirmed cases of poliomyelitis, measles, tetanus and tuberculosis).

- Classes of reporting of communicable diseases, with examples of 1st, 2nd and 3rd classes for VPD.

- When and how to report different classes of VPD.

- Types of data to be reported on immediate, weekly and monthly reports for childhood VPD.

- Name of report submitted in case of absence of poliomyelitis (zero report).

- Different preventive and control measures of some cases of VPD. 


\section{Statistical analysis}

Statistical analysis was conducted using SPSS, version 13. For the surveillance questionnaire, the performance indicators were calculated using WHO methods [10]. For the knowledge questionnaire, a knowledge score was calculated. Responses to each question were scored from $0-2$ ( 0 for incorrect answer or don't know, 1 for incomplete answer and 2 for correct complete answer). The total knowledge score ranged from 0-52 and was graded as follows: poor score: $<26$, fair score: $26-34.5$, good score: $>$ 34.5. The chi-squared test was calculated, or the Fisher exact test when the cells had a frequency of $\leq 5$. Results were considered statistically significant with a $P$-value $<$ 0.05 .

\section{Results}

Table 1 shows that the national surveillance manual was present in $57.6 \%$ of the selected health facilities. It was observed that the percentage of facilities that correctly filled the clinical register of childhood VPD was $60.6 \%$. Regarding the ability to confirm cases of VPD, observation revealed that $60.6 \%, 51.5 \%, 48.5 \%$ and $24.2 \%$ of health facilities had the ability to collect sputum, stool, blood and cerebrospinal fluid samples respectively. Regarding the capacity to handle specimens, $60.6 \%$ of facilities had a functional cold-chain supply, $42.4 \%$ had transport media and $48.5 \%$ had packing materials.

Table 1 also shows that $36.4 \%$ of health facilities lacked the appropriate surveillance forms for reporting of childhood VPD in the preceding 6 months. In only one-third of health facilities did the last monthly summary report agree with the clinical register for diseases targeted for eradication (poliomyelitis) and for elimination (measles).
The table also shows that the percentage of health facilities that had the correct number of weekly reports in the 3 months preceding the study (12 reports) was only $27.3 \%$, while the percentage was slightly better $(39.3 \%)$ regarding the correct number of monthly reports (3 reports). As regards the timeliness of reports, only $27.3 \%$ of health facilities submitted the weekly reports on time in the 3 months preceding the study.

Regarding data analysis, the results of the study revealed that no computerized database system was available at the health facility level, analysis of data was limited and generally data were analysed at the district level. One-third of the facilities conducted analysis of data by place, 39.3\% by time, while prepared line graphs were found in only $12.1 \%$ of the health facilities. In $27.3 \%$ of health facilities, health care workers reported that they had an action threshold for at least 1 of the country-priority diseases; however, observation showed that the action threshold for poliomyelitis was found in $18.2 \%$ of the facilities and for measles in $15.2 \%$.

Regarding epidemic preparedness and response, Table 1 shows that $57.6 \%$ of the facilities had a case management protocol for 1 epidemic-prone disease, and $60.6 \%$ implemented prevention and control measures based on local data.

The presence of at least 1 feedback report from a higher level during the preceding 1 year was found in $24.2 \%$ of the facilities, while a surveillance performance supervision review in the preceding 6 months was present in only $18.2 \%$. Training on surveillance was reported by $66.7 \%$ of health workers.

Assessment of the availability of surveillance resources showed that $63.6 \%, 54.5 \%$, $84.8 \%, 48.5 \%$ and $6.1 \%$ of the health fa-

المجلة الصحية لشرق المتوسط، منظمة الصحة العالمية، المجلد الخنامس عشر، العدد ب، 9 +. 
Table 1 Performance indicators of childhood vaccine-preventable diseases surveillance system at health facilities in Jeddah

\begin{tabular}{lcc}
\hline Item & $\begin{array}{c}\text { No. of facilities } \\
(\boldsymbol{n}=\mathbf{3 3 )}\end{array}$ & $\%$ \\
\hline Presence of surveillance manual & & \\
Reported (yes) & 19 & 57.6 \\
Observed (yes) & 19 & 57.6
\end{tabular}

Case detection and registration

Clinical registry

Reported (present)

Presence of vaccine-preventable diseases standard case definition

Reported (yes)

Observed (yes)

Ability to confirm cases

Ability to collect sputum sample:

Reported (yes)

Observed (presence of collection materials)

Ability to collect stool sample:

Reported (yes)

Observed (presence of collection materials)

Ability to collect blood or serum sample:

Reported (yes)

Observed (presence of collection materials)

Ability to collect CSF sample:

Reported (yes)

Observed (presence of collection materials)

Capacity to handle all samples:

Reported (yes)

Observed (presence of working cold-chain)

Observed (presence of transport media for specimens)

Observed (presence of packing material for shipment of specimens)

Data reporting

Lack of appropriate surveillance forms in last 6 months

Last monthly report agreed with the register for:

Disease targeted for eradication (poliomyelitis)

Disease targeted for elimination (measles)

Epidemic-borne disease (meningitis)

Disease of major public health importance (meningitis)

Correct number of weekly reports in last 3 months 
Table 1 Performance indicators of childhood vaccine-preventable diseases surveillance system at health facilities in Jeddah (concluded)

\begin{tabular}{|c|c|c|}
\hline Item & $\begin{array}{l}\text { No. of facilities } \\
(n=33)\end{array}$ & $\%$ \\
\hline \multicolumn{3}{|l|}{ Analysis of data } \\
\hline Description by place & 11 & 33.3 \\
\hline Description by time & 13 & 39.3 \\
\hline Description by line graph & 4 & 12.1 \\
\hline $\begin{array}{l}\text { Presence of action threshold for a country-priority disease } \\
\text { (reporting) }\end{array}$ & 9 & 27.3 \\
\hline $\begin{array}{l}\text { Presence of action threshold for a country-priority disease } \\
\text { (poliomyelitis) }\end{array}$ & 6 & 18.2 \\
\hline $\begin{array}{l}\text { Presence of action threshold for a country-priority disease } \\
\text { (measles) }\end{array}$ & 5 & 15.2 \\
\hline Presence of demographic data & 5 & 15.2 \\
\hline \multicolumn{3}{|l|}{ Epidemic preparedness } \\
\hline disease & 19 & 57.6 \\
\hline \multicolumn{3}{|l|}{$\begin{array}{l}\text { Epidemic response } \\
\text { Implementation of prevention and control measure based on }\end{array}$} \\
\hline local data & 20 & 60.6 \\
\hline \multicolumn{3}{|l|}{ Feedback } \\
\hline $\begin{array}{l}\text { Presence of at least } 1 \text { feedback report from higher level during } \\
\text { the last year }\end{array}$ & 8 & 24.2 \\
\hline \multicolumn{3}{|l|}{ Supervision } \\
\hline $\begin{array}{l}\text { Presence of surveillance supervision report in the last } 6 \\
\text { months }\end{array}$ & 6 & 18.2 \\
\hline \multicolumn{3}{|l|}{ Training } \\
\hline $\begin{array}{l}\text { Staff received training on disease surveillance and epidemic } \\
\text { management }\end{array}$ & 22 & 66.7 \\
\hline \multicolumn{3}{|l|}{ Resources available } \\
\hline Stationery & 21 & 63.6 \\
\hline Computer & 18 & 54.5 \\
\hline Fax & 28 & 84.8 \\
\hline Vehicle & 16 & 48.5 \\
\hline Statistical package ${ }^{a}$ & 2 & 6.1 \\
\hline
\end{tabular}

aEpi-Info/SPSS.

CSF $=$ cerebrospinal fluid

cilities had stationery, computers, faxes, vehicles and statistical packages (Epi-Info/ SPSS) respectively.

Regarding the knowledge of health workers about surveillance activities, it was found that only about one-quarter (24.1\%) of health care providers had a satisfactory knowledge score, $29.3 \%$ had a fair score while about a half (46.6\%) obtained a poor score. After combining the fair and satisfactory knowledge scores, no statistically significant difference was found between

المجلة الصحية لشرق المتو سط، منظمة الصحة العالمية، المجلد الخامس عشر، العدد ب، 9 +. 
the health workers' level of knowledge and the type of facility or sex $(P>0.05)$ (Table 2). No statistically significant difference was found between the level of knowledge of those who had attended a training course on surveillance and those who had not $(P>$ 0.05 ). On the other hand, respondents with a higher level of education (university or postgraduate degree), physicians and those with shorter work experience $(<10$ years $)$ had statistically significant better knowledge scores compared to others $(P<0.05)$.

\section{Discussion}

Public health surveillance systems provide information for action against infectious disease threats [11] and evaluating these systems is necessary to ensure that problems of public health importance are being monitored efficiently and effectively $[12,13]$.

Standardized case definitions for diseases under surveillance are important for providing uniform criteria for reporting cases [12]. The results of the present study revealed that the percentage of health facilities with access to the official standard case definition of childhood VPD was 57.6\%. This low rate may be attributed to a lack of available case definitions at health facilities or a lack of knowledge of health workers about them. However, the rate reported from the present study is better than that

\begin{tabular}{|c|c|c|c|c|c|c|}
\hline \multirow[t]{2}{*}{ Variable } & \multicolumn{2}{|c|}{ Poor knowledge } & \multicolumn{2}{|c|}{$\begin{array}{c}\text { Fair/satisfactory } \\
\text { knowledge }\end{array}$} & \multirow[t]{2}{*}{$\chi^{2}$} & \multirow[t]{2}{*}{$P$-value } \\
\hline & No. of staff & $\%$ & No. of staff & & & \\
\hline \multicolumn{7}{|l|}{ Type of health facility } \\
\hline Primary health care & 21 & 52.5 & 19 & 47.5 & 1.80 & 0.17 \\
\hline Hospital & 6 & 33.3 & 12 & 66.7 & & \\
\hline \multicolumn{7}{|l|}{ Sex } \\
\hline Male & 10 & 34.5 & 19 & 65.5 & 3.39 & 0.06 \\
\hline Female & 17 & 58.6 & 12 & 41.1 & & \\
\hline \multicolumn{7}{|l|}{ Educational level } \\
\hline University/postgraduate & 7 & 29.2 & 17 & 70.8 & 4.97 & 0.02 \\
\hline Less than university & 20 & 58.8 & 14 & 41.2 & & \\
\hline \multicolumn{7}{|l|}{ Job } \\
\hline Physician & 5 & 26.3 & 14 & 73.7 & 4.65 & $0.02^{\mathrm{a}}$ \\
\hline Other specialty & 22 & 56.4 & 17 & 42.6 & & \\
\hline \multicolumn{7}{|l|}{ Period of working (years) } \\
\hline$<10$ & 12 & 34.3 & 23 & 65.7 & 5.33 & 0.02 \\
\hline $10+$ & 15 & 65.2 & 8 & 34.8 & & \\
\hline \multicolumn{7}{|c|}{ Received training on surveillance } \\
\hline Yes & 13 & 48.1 & 14 & 51.9 & 0.05 & 1.00 \\
\hline No & 14 & 45.2 & 17 & 54.8 & & \\
\hline Total & 27 & 46.4 & 31 & 53.4 & & \\
\hline
\end{tabular}

a Fisher exact test. 
from a study from Uganda in 2000, where only $35 \%$ of facilities had the official standard case definition of EPI diseases [14].

In our study $60.6 \%$ of facilities correctly and completely filled the clinical register for VPD. An earlier study in 2000 in Jeddah to evaluate communicable diseases reporting found that the usefulness of reporting diminished because of incomplete, absent or incorrect filling of personal and disease data [15]. The problem of incorrect and incomplete form-filling may be due to a lack of knowledge of the people in charge of surveillance about how to fill registers and reports. Our results agree with the study in Uganda where the corresponding rate was $56 \%$ [14]. In the United States of America (USA), despite state and local laws requiring medical providers to report notifiable infectious diseases to the public health authorities, a literature review of 33 published studies between 1970 and 1999 revealed that the percentage of complete reports varied from $9 \%$ to $99 \%$ and was most strongly associated with the disease being reported [16].

Many health facilities in our study did not have the capacity to properly collect, store and transport specimens of suspected cases of VPD. This may be because cases that need laboratory investigations are referred to more advanced laboratories. This result concurs with the results of a study of VPD surveillance in Georgia (a former republic of the Soviet Union) in 2002 [8].

Results from Uganda showed that $65 \%$ of facilities lacked an adequate supply of reporting forms during the 6 months preceding the study [14]. The corresponding figure from our study was better, with only $36.4 \%$ of facilities lacking the appropriate forms. This is perhaps due to differences in the resources available for health care between the countries. However, our rate still requires improvement. A study to as- sess the structure and performance of infectious disease surveillance using the health management information system (HMIS) in Tanzania reported a slightly better rate (27\% of facilities lacked theses forms) [3]. This better rate may be because the WHO Regional Office for Africa approved the integrated disease surveillance and response strategy for strengthening infectious disease surveillance and response capacity in Tanzania, where it has been applied since 1998.

In about one-third of the health facilities in the present study the monthly report agreed with the clinical register (for diseases targeted for eradication, elimination, epidemic-prone diseases and those with major public health importance). This low rate may be attributed to a lack of health workers' knowledge about these diseases, their classification, and when and how to report them. However, the current rate is slightly better than that obtained from Uganda (29\%) [14].

Under-reporting of infectious diseases remains a major problem in communicable diseases surveillance [17]. A study from the USA in 1999 found that only $33 \%$ of the diseases on the list for national surveillance were actually reportable in each of the responding States [12]. In our study the percentage of health facilities that had submitted the correct number of weekly reports in the 3 months preceding the study was only $27.3 \%$. This rate is low and requires much improvement. In Germany in 2003, the first evaluation of the surveillance systems of notifiable diseases using an electronic database system revealed that their programme was very successful, with $90 \%$ of facilities transmitting data weekly [18]. This may be due to the benefits gained from application of an electronic database system, which is a much easier and less costly way of transmitting data.

المجلة الصحية لشرق المتو سط، منظمة الصحة العالمية، المجلد الخامس عشر، العدد ب، 9 +. 
Timeliness of reporting is a key performance measure of public health surveillance systems [19]. In the present study only $27.3 \%$ of health facilities submitted the correct number of weekly reports on time during the 3 months preceding the study. This low rate may be attributed to health workers' lack of understanding of the importance of timeliness of reporting. A slightly higher rate $(35 \%)$ was obtained from Tanzania [3]. Analysis of the National Notifiable Diseases Surveillance System in the USA showed that long lag times in reporting and variability in reporting across states limited the usefulness of the data [19]. For these reasons, a computer database, the Public Health Surveillance Knowledgebase was established in 2003 in order to facilitate the integration of information sources [20]. Even so, when database systems for notifiable diseases are in place, such as in New South Wales, Australia, there may be factors limiting their ability to provide timely and accurate data [21].

We found that the analysis of data about VPD in children at the health facility level was limited; only about one-third of facilities conducted analysis of cases by place and time, while only $12.1 \%$ prepared line graphs. This low figure may be attributed to analysis of data at the higher (district) level and lack of statistical packages (such as SPSS or Epi-info) or people trained to use them at the health facility level. Our result agrees with a critical review of infectious diseases surveillance in Gaza, Palestine, where prepared line graphs were reported from $10 \%$ of health facilities [17]. These results also agree with that from an assessment of infectious disease surveillance systems in Armenia where very few surveillance data were computerized, analysed or used to develop or evaluate public health policy [22].
It was reported from the Tanzanian study that $29 \%$ of medical offices had population denominators to use for data analyses [3]. On the other hand, a lower rate (15.2\%) was obtained in our study. This can be attributed to a lack of availability of census data at the health facilities, and to the analysis of these data at district level.

While $27.3 \%$ of health facilities reported having a threshold action for one of the country-priority diseases, on observation it was found that an action threshold for poliomyelitis was found in only $18.2 \%$ of facilities and for measles in $15.2 \%$. Results from Uganda showed that $27 \%$ of health facilities had a threshold action for epidemic-prone diseases [14].

Regarding epidemic preparedness and response, $57.6 \%$ of facilities had a case management protocol for 1 epidemic-prone disease and $60.6 \%$ had implemented prevention and control measures based on local data. The rate obtained in our study requires much improvement by increasing the availability of management protocols and training health workers on these. A lower rate was reported from Uganda, where $50 \%$ of facilities conducted community prevention and control measures [14]. On the other hand, better results were obtained from Tanzania, where $79 \%$ of facilities using HMIS implemented prevention and control measures based on local data [3].

Lack of feedback from the reporting centres to the health centres hampers improvements in clinical practice [22]. In our study the presence of at least 1 feedback report (during the preceding 6 months) was found in only $24.2 \%$ of facilities, and a performance supervision review was found in $18.2 \%$. Better results were obtained from the Tanzanian study, where $42 \%$ of facilities using HMIS received supervision or feedback during the same time period [3]. 
On the other hand, in Uganda, feedback was found in $15 \%$ of facilities and supervision in $32 \%[14]$.

In the present study two-thirds of health workers in charge of surveillance reported receiving training. This agrees with results from Uganda where $62 \%$ of health providers received training on surveillance [14]. On the other hand, a higher rate $(81 \%)$ was reported from Tanzania [3].

Our study found a deficiency of resources needed for surveillance at the health facility level, such as computers and statistical software. This may also be due to the analysis of data at district level. Similar results were obtained from Brazil, where there was a lack of equipment and a deficiency in staff qualifications [23]. The Ugandan study reported a greater deficiency in resources than our study; stationery was found only in $25 \%$ of facilities [4].

Regarding knowledge of health providers about different items of surveillance, about a half $(46.6 \%)$ of them in our study had a poor knowledge score; only about a quarter of health providers had a satisfactory knowledge score. The low standard of knowledge is of concern and needs improvement. The results of a study in 1997 for assessment of surveillance and control of poliomyelitis in Egypt showed that the knowledge of some health workers was incomplete [24]. The results of a focus group discussion to assess knowledge about VPD surveillance in Georgia in 2003 showed that health providers had poor knowledge about surveillance and the regulations and accordingly the level of these activities was minimal [25]. In our study, no statistical significant difference was found between the knowledge of health workers who received training about surveillance and those who did not. This indicates that the training courses need to be revised. The results also showed that physicians who had university degrees and above, and those who with shorter work experience, had better knowledge scores. The reason for this may be that graduate health care providers, especially those who are recently graduated, usually study the topic of reporting and surveillance of infectious diseases during their course at university.

It is concluded from the present study that there are deficiencies in some areas of the surveillance systems for childhood VPD in the health facilities of Jeddah governorate. Given the importance of surveillance in monitoring and controlling VPD, there is an urgent need to address the deficiencies in resources, reporting and knowledge within the health facilities in order to correct them and improve the surveillance system for childhood VPD in Jeddah. The development of continuing education, staff motivators and electronic database systems are among the strategies recommended in this regard.

\section{Acknowledgements}

The authors would like to thank all the students who participated in collection of the data and all those who facilitated and helped in accomplishing this work. Special thanks go to the manager of Jeddah Directorate of Health Affairs, the head of the communicable disease department, and the head of the medical license department. In addtion we are grateful to the head of the surveillance unit at district level for facilitating the study. Thanks are also extended to all staff of the health facilities visited for generously providing the time to help in data collection. 


\section{References}

1. Wigzell H. A European CDC? Science, 2005, 307(5716):1691.

2. Documentation of integrated disease surveillance and response implementation in the African and Eastern Mediterranean Regions. Report of a WHO meeting. Harare, Zimbabwe, 4-15 November 2002. Geneva, World Health Organization, 2003 (WHO/CDS/CSR/LYO/2003.5).

3. Nsubuga $P$ et al. Structure and performance of infectious disease surveillance and response, United Republic of Tanzania, 1998. Bulletin of the World Health Organization, 2002, 80(3):196-203.

4. Updated guidelines for evaluating public health surveillance systems: recommendations from the guidelines. Morbidity and mortality weekly report, 2001, 50:1-36.

5. Desenclos JC. Surveillance des maladies infectieuses: principes et l'organisation en France en 2005 [Surveillance of infectious diseases: principles and organization in France in 2005]. Médecine et maladies infectieuses, 2005, 35(5):232-44.

6. Nelesone $\mathrm{T}$ et al. Short communication: strengthening sub-national communicable disease surveillance in a remote Pacific Island country by adapting a successful African outbreak surveillance model. Tropical medicine and international health, 2006, 11(1):17-21.

7. John TJ et al. Communicable diseases monitored by disease surveillance in Kottayam district, Kerala state, India. Indian journal of medical research, 2004, 120(2):70-2.

8. Ministry of Labor, Health and Social Affairs and National Center for Disease Control. Assessment of vaccine preventable disease surveillance systems in Georgia. Bethesda, Maryland, The Partners for Health Reformplus Project, Abt Associates Inc., 2002 (Technical Report No. 028).

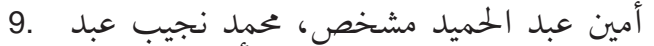

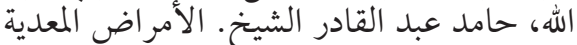

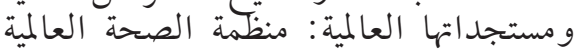

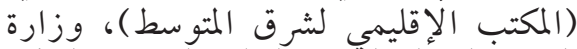

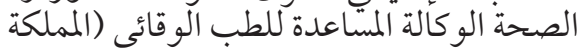
العربية السعودية)، الوكالة 2004.

10. Protocol for the assessment of national communicable disease surveillance and response systems. Geneva, World Health Organization, 2001 (WHO/CDS/CSR/ ISR/2001.2).

11. Global health: challenges in improving infectious disease surveillance systems. Washington DC, United States General Accounting Office, 2001 (GAO-01-722).

12. Roush $S$ et al. Mandatory reporting of diseases and conditions by health care professionals and laboratories Journal of the American Medical Association, 1999, 282(2):164-70.

13. Hopkins RS. Design and operation of state and local infectious disease surveillance systems. Journal of public health management and practice, 2005, 11(3):184-90.

14. Assessment of infectious disease surveillance-Uganda, 2000. Morbidity and mortality weekly report, 2000, 49(30):68791.

15. Bakarman MA et al. Assessment of reporting and recording system of communicable diseases in Jeddah Region. Saudi medical journal, 2000, 21(8):751-4.

16. Doyle TJ et al. Completeness of notifiable infectious disease reporting in the United States: an analytical literature review. American journal of epidemiology, 2002, 155(9):866-74.

17. Awad $R$ et al. A critical review of the infectious diseases surveillance system in the Gaza Strip. Eastern Mediterranean health journal, 2001, 7(1/2):274-9. 
18. Krause $\mathrm{G}$ et al. Erste Bewertung der Überwachungssysteme der meldepflichtigen Krankheiten gemäß der Infektionskrankheit Kontrolle Gesetz in Deutschland [First evaluation of the surveillance systems of notifiable diseases under the infectious disease control law in Germany]. Gesundheitswesen, 2003, 65(Suppl. 1):S8-12.

19. Jajosky RA, Groseclose SL. Evaluation of reporting timeliness of public health surveillance systems for infectious diseases. BMC public health, 2004, 4:29.

20. Doyle TJ et al. PHSkb: A knowledge base to support notifiable disease surveillance. BMC medical informatics and decision making, 2005, 5:27.

21. Persson $L$ et al. Notifiable diseases database system: review and development strategy. New South Wales public health bulletin, 2004, 15(1/2):10-2.

22. Wuhib $T$ et al. Assessment of the infectious diseases surveillance system of the Republic of Armenia: an example of surveillance in the Republics of the former Soviet Union. BMC public health, 2002, 2:3-10.

23. Leite JA, Assis MM, de Cerqueira EM. Vigilância epidemiológica no sistema local de saúde [Epidemiologic surveillance in the local health system]. Revista brasileira de enfermagem, 2003, 56(2):178-83.

24. Heddaya ZM. Surveillance and control of poliomyelitis in Alexandria [PhD thesis]. Alexandria, Egypt, Department of Epidemiology, High Institute of Public Health, University of Alexandria, 1997.

25. Djibuti M et al., eds. Knowledge, attitudes, and behaviors toward VPD surveillance among health care providers and community members in Georgia: Focus Group Discussion Report. Bethesda, Maryland, Abt Associates, Partners for Health Reform Plus, 2003. 